\title{
Orders Loading and Release in Flow Shops including Outsourcing Networks
}

\author{
Tatsiopoulos, I.P.*, A. Batsis, A. and G. Papadopoulos \\ * Professor in Industrial Management, National Technical University of \\ Athens, 15780 Zografos, Athens, Greece, Tel:+3010 7723572, Fax: +3010 \\ 7723571
}

\begin{abstract}
Purpose of this paper is to analyse and compare the behavior of workload control models in flow shops of both the MTO (Make-To-Order) and MTS (Make-To-Stock) classes. A simulation model has been built, where a manufacturing cell is loaded through an input control mechanism with shop orders coming from a "pool". The "pool" itself is fed with planned orders coming from an MRP system. The MRP system releases production orders every planned period and the input control mechanism decides for the actual release of work orders. Conclusions are drawn for the performance of the system with or without an MRP system and with or without the input control mechanism in MTO and MTS environments. Compared to the pure flow shop routing, any set of stations might be excluded from the routing or replaced by subcontractors belonging to an outsourcing network of the manufacturing company. Thus, the general flow shop may still show routing variety with respect to routing lengths, though there is one flow direction with outsourcing interruptions.
\end{abstract}

\section{Introduction and problem definition}

The Orders Release function includes those activities, which must take place before an order defined by a planning system, can be released to an execution system. These activities are necessary to control the flow of information and orders passing from the planning system to the execution system and to ensure that the orders released have a reasonable chance of being completed by the time and in the quantity wanted. According to the above definition, Orders Release, at least in push production planning and control systems of the MRP II type (Manufacturing Resources Planning), forms the link between the production planning system and the shop floor control (SFC) system.

Please use the following format when citing this chapter:

Tatsiopoulos, I.P., Batsis, A. and Papadopoulos, G., 2008, in IFIP International Federation for Information Processing, Volume 257, Lean Business Systems and Beyond, Tomasz Koch, ed.; (Boston: Springer), pp. 75-92. 
Most of the order release models found in the research literature refer to job shops and make-to-order (MTO) manufacturing under the terms of input/output control or workload control. Research effort in the area of workload control for flow shops and make-to-stock (MTS) manufacturing driven by push MRP (Material Requirements Planning) systems is rather limited. The much discussed alternative family of pull production control systems of the CONWIP type (Hopp and Spearman, 2000) is not addressed or compared in the present study.

Out of the Hayes and Wheelwright (1979) well-known taxonomy of production systems, we select as our flow shop perspective the disconnected line flow, where product batches are produced on a limited number of identifiable routings (i.e. paths through the plant) and inventories can build up between work centres. In this general flow shop environment - as opposed to the pure flow shop, where each job has exactly the same routing - a movement between any combination of two workstations may occur, but the flow will always have the same direction. Compared to the pure flow shop routing, any set of stations might be excluded from the routing and replaced by subcontractors belonging to an outsourcing network of the manufacturing company. Thus, the general flow shop may still show routing variety with respect to routing lengths, though there is one flow direction with outsourcing interruptions. In industrial practice, the following two manufacturing settings are characteristic of the general flow shop type:

a) Sequenced operations through functionally organized departments. Many manufacturing companies produce a wide range of products through a more or less well-defined production process. The product flows from one department to another in a single direction. Sometimes the resulting schedules, lead times, and work-inprocess inventories exhibit the worst characteristics of those of the true job shop, in spite of the opportunities for a more thoroughly organized scheduling system, which this form of production organization makes possible (McGee and Boodman, 1967).

b) Manufacturing cells. In this case, a uniform range of similar products flows through the manufacturing cell. Here, too much effort has been devoted on detailed scheduling algorithms within SFC systems, while there is a scarcity of publications on shop orders release loading and release as a link between the MRP system and the SFC system.

Flow shops may belong to either the MTO (Make-To-Order) or the MTS (MakeTo-Stock) types of manufacturing systems. In both cases the focus of shop orders loading and releasing should be shifted from balancing the workload of individual work centres into balancing the flow through flow shops (balance flow not capacity, Goldratt, 1982). Within this setting, SFC is organized to enhance the ability of the system to maintain an uninterrupted flow of materials. The orders release and detailed assignment activities frequently take place at the same time. The order in which the jobs are to be processed is determined not on the shop floor but in the shop orders loading and release phase.

Section 2 of this paper presents a literature review and state of the art of the orders release and workload control field. Section 3 describes a new concept for workload conrol in flow shops based on Goldratt's ideas about balancing flow instead of capacity, Section 4 includes extensive simulation experiments and Section 5 concudes the research work. 


\section{Literature review and state of the art}

Observing the Orders Release function in the industrial practice, it can be seen that not all jobs (production orders, shop orders or work orders) are released to the shop immediately after it becomes theretically possible to do so. Rather they are retained in a "suspence file", thus being nothing more than a notation in a scheduling book which takes the form of a "job pool" (Irastorza and Dean, 1974). Utilisation of this job pool can reduce the level of work-in-process and allow more control over the flow of jobs through the shop. This is in fact equivalent to cleaning up the shop floor by not allowing excess jobs to move into the shop. The literature on orders release is sparce in comparison to the literature on detailed scheduling and sequencing. However, the articles that have been written indicate that effective orders release is a prerequisite to the development of a good SFC system.

Under the job pool concept the shop consists of a pool of jobs not yet released to the floor plus distinct work centres with a queue of jobs in front of each. Loading consists of the release into the shop of a subset of the pool every scheduling period. The scheduling period can be a shift, a day, a week, etc.

The key to the successful use of the job pool is the availability of a good mechanism to select those jobs from the pool that should be moved to the factory floor. This mechanism is in fact the Input/Output Control (IOC) methodology. The idea of Input/Output Control was first mentioned by White (1970) and further supported by Plossl and Welch (1979) some years later. Since then, many authors (Bertrand and Wortmann 1981, Tatsiopoulos and Kingsman 1984, Wiendahl 1987, Bechte 1988, Wein 1988, Glassey and Resende 1988, Kingsman et al 1989, Bertrand et al 1990) have studied the subject.The method calculates planned input, planned output, planned queue and deviations at each work centre, in order to decide on the release of shop orders. Variations to the Input/Output Control concept appear in the literature under the name workload control, work backlog control and load-oriented orders release.These concepts are mainly developed for job shop environments and the pure job shop model has been used for evaluation. Different approaches have been proposed, which all aim at keeping work backlogs at a low and stable level.

(a) The workload control concept developed at the IFA in Hannover (Wiendahl, 1995), estimates the input from jobs upstream to the direct backlog (queue) of a workstation. The estimated direct backlogs workloads are subjected to norms.

(b) The workload control concepts developed in Eindhoven (Bertrand et al, 1990) and Lancaster (Kingsman et al, 1989) avoid estimating the input to the direct backlogs. They aggregate the direct and the indirect workload of a workstation by adding them and subject this aggregate workload (or backlog) to a norm.

Effort in the area of flow shops or manufacturing cells is limited. Bertrand and Van Ooijen (1996), Tatsiopoulos and Prastacos [16], Enns (1995), and Oosterman et al (2000) are among the authors that have studied the application of input control methodology in a flow shop type of production system.

The main objective of this paper is to study and compare the behaviour of workload control in various forms of flow shops, i.e. the MTO (Make To Order) 
flow shop without using an MRP system and the MTS (Make To Stock) flow shop using an MRP system. A new balancing flow principle is developed for controlling the input of work into the flow shop, which is called B-LOB (Backlog Line-OfBalance). Furthermore, the paper tries to investigate the influence of an MRP system to the pool of unreleased orders by means of a releasing mechanism between the MRP system and the flow shop. Conclusions are drawn for the performance of the system with or without an MRP system and with or without the input control mechanism in MTO and MTS environments.

\section{Workload control in flow shops}

The input/output control or workload control method obviously needs to know input and output of work centres at the very moment they happen. However, input information is considered reliable only for gateway work centres. On the contrary, the timing of work input to the following downstream work centres is highly unpredictable.

To solve this problem an aggregate input/output approach can be used (Kingsman et al, 1989) relying on the aggregate released backlog instead of actual queues. The aggregate released backlog of a work centre is defined as the sum of all released work on the shop floor for this particular work centre, regardless of where it resides, either in the centre's actual queue or in the queue of any other previous (upstream) work centre.

The main advantage of the aggregate released backlog as a planning tool is that all the operations of a job to be released join the released backlogs of the corresponding work centres in the job sequence simultaneously at the job release time and stay there until the job is processed and leaves the work centre. This means that input to the aggregate released backlog can be easily controlled for all the work centres, gateway or downstream they maybe, since there is no need to forecast uncertain operation transit and arrival times.

The mathematical expressions for the Released Backlog, the Input/Output relationship and the Released Backlog Length are as follows:

$$
\begin{gathered}
R B(J, T)=\sum_{R} \sum_{F} W(I, F(J), T) \\
R B(J, T)=R B(J, 0)+\sum_{t=1}^{T} R(J, t)-\sum_{t=1}^{T} C(J, t) \\
R B(J, T)=R B(J, T-1)+R(J, T)-C(J, T) \\
R B L(J, T)=R B(J, T) / C(J, T) \text { where, }
\end{gathered}
$$

$\mathrm{RB}(\mathrm{J}, \mathrm{T})$

$\mathrm{W}(\mathrm{I}, \mathrm{F}(\mathrm{J}), \mathrm{T})$

$\mathrm{F}$

$\mathrm{R}$
$=$ Released Backlog of work centre $\mathrm{J}$ at period $\mathrm{T}$.

$=$ Work content of operation of job I to be carried out in the future at work centre $\mathrm{J}$, where job I resides at time $\mathrm{T}$ in the queue of wok centre $F$.

$=$ Number of work centres in the shop.

$=$ Released jobs to the shop floor. 
$\mathrm{R}(\mathrm{J}, \mathrm{T})$

$\mathrm{RBL}(\mathrm{J}, \mathrm{T}) \quad=$ Released Backlog Length of work centre $\mathrm{J}$ at period $\mathrm{T}$.

$\mathrm{C}(\mathrm{J}, \mathrm{T})$

$\mathrm{RB}(\mathrm{J}, 0)$

$=$ Amount of work that is released during period $\mathrm{T}$ for work centre J.

$=$ Planned capacity of work centre $\mathrm{J}$ at period $\mathrm{T}$.

$=$ Initial Released Backlog of work centre J.

The queue $\mathrm{Q}(\mathrm{J}, \mathrm{T})$ of work centre $\mathrm{J}$ is only a part of its Released Backlog $\mathrm{RB}(\mathrm{J})$. The rest will be called the Indirect Released Backlog IRB $(\mathrm{J}, \mathrm{T})$ of work centre $\mathrm{J}$ at period $\mathrm{T}$.

$R B(J, T)=Q(J, T)+\operatorname{IBR}(J, T)=\sum_{I} W(I, J(J), T)+\sum_{I} \sum_{L \neq J} W(I, L(J), T)$ where,

$\mathrm{W}(\mathrm{I}, \mathrm{J}(\mathrm{J}), \mathrm{T})=$ Work content of operation of job I to be carried out at work centre $\mathrm{J}$, where job I presently resides in the queue of work centre $\mathrm{J}$.

$\mathrm{W}(\mathrm{I}, \mathrm{L}(\mathrm{J}), \mathrm{T})=$ Work content of operation of job I to be carried out in the future at work centre $\mathrm{J}$, where job I presently resides in the queue of work centre L.

$\mathrm{L}$ $=$ All the work centres apart from work centre $\mathrm{J}$.

The Released Backlog Length $\operatorname{RBL}(\mathrm{J}, \mathrm{T})$ is equal to the sum of the Indirect Released Backlog Length IRBL(J,T) and the Queue Length QL(J,T).

$$
R B L(J, T)=Q L(J, T)+\operatorname{IRBL}(J, T)
$$

The behaviour of the relation between the Indirect Released Backlog Length and the Queue Length within their sum, which is the Released Backlog Length, has to be carefully analysed. On the nature of this relation depends the ability of the planner to control the average queue lengths through aggregate Input/Output Control of the released backlogs of all the work centres. In the case of the flow shop, where a distinct main material and order flow can be found, a Mean Position MP(J) can be defined for all the work centres belonging to the main flow:

$$
M P(J)=\sum_{I} P(I, J) / N \text { where, }
$$

$\mathrm{MP}(\mathrm{J})=$ Mean position of work centre $\mathrm{J}$. It is the mean number of work centres passed through before a job getting to work centre $\mathrm{J}$.

$\mathrm{P}(\mathrm{I}, \mathrm{J}) \quad=$ Position of work centre $\mathrm{J}$ in the job sequence of job $\mathrm{I}$.

$\mathrm{N} \quad=$ total number of jobs passing through work centre $\mathrm{J}$ over a long time period.

Assuming that the main flow is well balanced, i.e. the same mean waiting time and queue length applies for all the work centres across the path, the following conditions will hold:

a) Input rate to work centre $J=$ Output rate from work centre $J$.

$$
\left.\sum_{I} \sum_{L \neq J} W(I, L(J)) / C(J)\right) * P=\sum_{I} W(I, J(J) / C(J)
$$

$P_{L J}=$ The probability of work flowing from work centre $\mathrm{L}$ to work centre $\mathrm{J}$.

$$
\begin{gathered}
\text { Assuming that } \sum_{L} P_{L J} \cong P_{J-1 J} \cong 1 \text { then } \\
\sum_{I} W(I, J-1(J)) / C(J)=\sum_{I} W(I, J(J)) / C(J)
\end{gathered}
$$


where $\mathrm{J}-1$ is the work centre previous to $\mathrm{J}$ in the main flow of work in the flow shop.

b) Output rate from work centre $J-1=$ Input rate to work centre $J$.

$\sum_{I} W(I, J-1(J-1)) / C(J-1)=\sum_{I} W(I, J-1(J)) / C(J)=\sum_{I} W(I, J(J)) / C(J)$

Working the same way across the chain of work centres in the main flow upstream to the first work centre, we get:

$$
\begin{aligned}
& \sum_{I} \sum_{L \neq J} W(I, L(L)) / C(L)=\sum_{I} \sum_{L \neq J} W(I, L(J)) / C(J) \Rightarrow \sum_{L \neq J} Q L(L)=I R B L(J) \Rightarrow \\
& \sum_{L \neq J} Q L(L)+Q L(J)=R B L(J) \Rightarrow M Q L^{*} M P(J)=R B L(J)
\end{aligned}
$$

where, MQL is the common mean queue length over all the work centres.

Therefore, the released backlog length of a work centre is equal to the product of the mean position of the work centre in the main flow and the mean queue length. The indirect released backlog length of work centre $J$ is equal to the sum of the queue lengths of all the previous work centres a job has to pass before it is processed at work centre $\mathrm{J}$.

The concept of discrete orders release (not time-phased) using the Input/ Output Control (IOC) methodology in flowshops including outsourcing networks is described below:

Whole partner factories performing a single manufacturing operation or a sequence of operations are considered as black box capacity units. The role of the "order pool" is played by the unreleased Production Orders (PPOs) file.

- At the supply chain release level a workload control method has been developed, which is directed rather to the balance of production flow through the supply chain rather than the balance of capacities. This method is characterised by two main principles: Production orders are allowed to remain unreleased for up to a maximum of a few time periods to form a backlog of unreleased orders (pool), with the maximum delay added to the manufacturing time to obtain the lead time.

- Production orders are released periodically in such a way that each partner or indoor work centre and all its downstream partners.work centres are provided with a balanced inflow of work so that their mean released backlogs lengths (actual queue plus released work residing in the upstream partners/work centres) do not exceed their maximum limits.

To solve this problem an aggregate input/output approach can be used relying on the aggregate released backlog instead of actual queues. The aggregate released backlog of a subcontracting partner is defined as the sum of all released work for this particular partner, regardless of where it resides, either in the partner's actual queue or in the queue of any other previous (upstream) partner.

The main advantage of the aggregate released backlog as a planning tool is that all the operations of a production order to be released join the released backlogs of the corresponding partners in the order sequence simultaneously at the order release 
time and stay there until the order is processed and leaves the partner. This means that input to the aggregate released backlog can be easily controlled for all the partners.

The basic tool of our approach for making input control interactive decisions is the backlog length chart (Figure 1). A basic concept of this tool is the Backlog Lineof-Balance (B-LOB). This concept has its origin in the Line-of-Balance (LOB) technique of production control in batch production (Bestwick and Lockyer, 1982). In our case the LOB concept has been combined with the Input/Output Control (IOC) concept and produced the B-LOB technique which is suitable for applying IOC in flow shops. The characteristics of this graphical tool are:

(a) The bars represent backlog lengths of partners/work centres, i.e. relationships between backlogs and capacities. The backlog lengths are multiples of the backlogs and capacities. They change with the capacity even if the backlogs remain the same.

(b) The chart is not time-phased. The backlog lengths of all the partners are depicted at the same time period. On the contrary the classical load reports show time-phased capacity requirements of just one work centre at a time, so that the overall load situation cannot be grasped at a glance.

(c) All the operations of a production order are loaded simultaneously at the time period of order entry, so that the inaccurate loading due to the uncertainty of interoperation transit time is avoided.

(d) The released backlogs of downstream partners/work centres are multiples of the released backlog of the gateway partner/work centre. In the case of flow shops this is analoguous to the position of the work centre in the sequence of operations forming a "line-of-balance" for the ideally balanced shop (thick line profile in Figure 3).

(e) Norms of maximum and minimum backlog lengths are depicted on the chart. Actual performance can then be drawn on the chart, the difference between plan and performance becoming obvious. It is very useful when progressing because it is immediately obvious when corrective action needs to be taken.

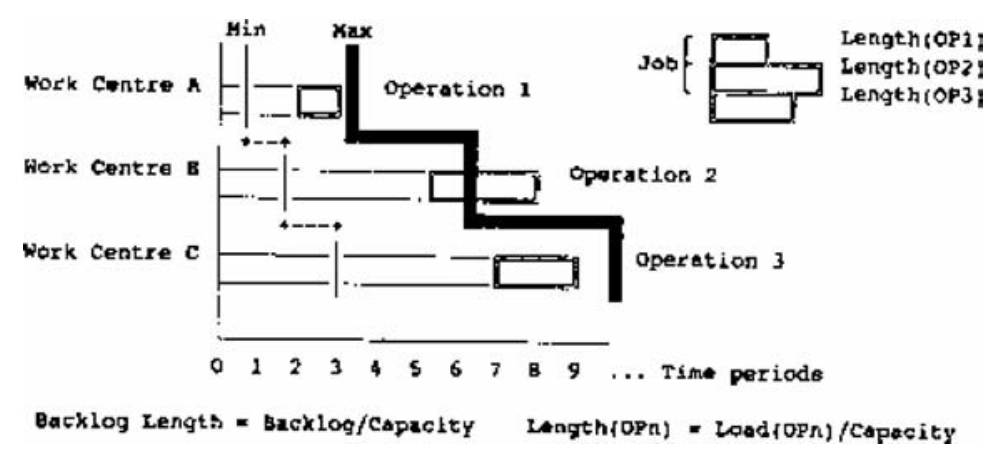

Fig. 1. Backlog length chart and Line-Of-Balance 
At the moment of an order release to the cell, there is a contribution to the total workload for each work centre, which the order will visit. The respective amount of work (set-up and process time), after the completion of an operation, is deducted from the total workload, the released backlog of work of the respective work centre. Every moment we know the total amount of workload, the released backlog, which resides in every work centre of the cell, and by controlling the levels of the released backlogs in each work centre, with predetermined norms, we ensure that the total backlog and the flow or work through the cell is smooth and controlled. Assumed is that the master plan (overall LOB-norm) is fixed by one central point in the manufacturing network, which the prime contractor who has direct contact to the customers. At the moment of an order release to the manufacturing network, there is a contribution to the aggregate released backlog of each partner/work centre, that the order will visit. After operation completion, the amount of work (set-up and process time) is deducted from the released backlog of the respective work centre. Every moment we know the released backlog of every partner/work centre, and by controlling the levels of the released backlogs in each partner/work centre, with the predetermined norms of the line-of-balance, we ensure that the backlog and the flow of work through the shop is smooth and controlled.

By means of the above methodology we can also control the operation lead times and the total manufacturing lead times, moreover to compute and apply more reliable delivery times for customer orders. Knowing the capacity of a partner/work centre, in standard labour hours per day, and the predetermined backlog of work for a certain work centre we can compute the mean lead time for the work orders. The mean lead time is equal to the ratio of the backlog of work and the output of work (capacity).

\section{The Simulation Model}

\subsection{The simulated manufacturing cell}

A flow shop in the form of a manufacturing cell (Figure 2) has been modelled using the ARENA simulation language. The product layout cell consists of five work centres. Each work centre has a functional layout with identical machines. The first work centre has one machine. The second, third and fourth work centres have two identical machines and the fifth work centre has three identical machines.

The manufacturing cell under study is capable of producing eight different product families, that are scheduled and released either a) by the MRP system in the case of a make-to-stock (MTS) business environment or b) by the order acceptance system in the case of a make-to-order (MTO) environment. Our purpose is to investigate the behaviour of the proposed shop loading and release method as well as the influence of the pool concept to the two different environments.

Each product family can have a number of similar products. The products that belong to the same family have physical (material, dimensions, weight) and functional (routing, set-up time, operation time) similarities. The natural flow of parts in the system is from work centre 1 to work centre 5 (Figure 2). Following the 
principle of a flow shop, an order is allowed to skip a work centre, however it is not allowed to flow inversely nor to revisit a work centre (backtracking).

The part routings for each family are given in Table 1 together with the five different product mixes that are examined in this study.

Table 1. Number of families, part routings and product mix

\begin{tabular}{ccrrllll}
\hline & & \multicolumn{5}{c}{ Product Mix } \\
\cline { 3 - 7 } Family & Routing & A1 & A2 & A3 & A4 & A5 \\
\hline 1 & $1-2-3-4-5$ & 0.125 & 0.050 & 0 & 0 & 0 \\
2 & $1-2-3-5$ & 0.125 & 0.050 & 0 & 0 & 0 \\
3 & $1-2-4-5$ & 0.125 & 0.050 & 0 & 0 & 0 \\
4 & $1-3-4-5$ & 0.125 & 0.125 & 0.2 & 0.125 & 0.05 \\
5 & $2-3-4-5$ & 0.125 & 0.125 & 0.2 & 0.125 & 0.05 \\
6 & $1-3-5$ & 0.125 & 0.200 & 0.2 & 0.250 & 0.30 \\
7 & $2-3-5$ & 0.125 & 0.200 & 0.2 & 0.250 & 0.30 \\
8 & $2-4-5$ & 0.125 & 0.200 & 0.2 & 0.250 & 0.30 \\
& Sum & 1.000 & 1.000 & 1.0 & 1.000 & 1.00 \\
\hline
\end{tabular}

The orders arrive under a Poisson distribution; in other words the time between arrivals follows the exponential distribution with a mean of 1.4 hours. This value is chosen as a result of initial pilot runs that produce a $90 \%$ average utilisation of the system. A new order that arrives to the system is assigned a number of attributes: the family number, the standard operation and set-up times, the order size, the standard MRP lead time, the due date and the earliest release date.

The family number for a newly arrived order is extracted from a discrete probability distribution according to a predetermined product mix. The product mix is the probability for a newly arrived order to belong in one of the eight possible families.

According to the different product mixes there are five different types of experiments. There is the ability to give zero probability for any family. Thus we force the cell to produce fewer families of products and by the appropriate selection to have a cell with less than five work centres (see Table 1).

The operation processing times follow a uniform distribution. The earliest release date is the next planned order release period. The MRP system plans orders on a weekly planning period. Every week (40 simulated hours) shop orders are planned by the MRP system and loaded into the pool. The pool is then responsible to release orders according to the current Aggregate Workload of the manufacturing cell. The objective of the releasing mechanism is to control and balance the released workload according to predetermined norms following the B-LOB principle.

Calculation of order due dates is based on the Total Manufacturing Lead Time, which is the sum of the time spent in the pool (Pool Delay Allowance) and the time spent in the manufacturing cell (Throughput Time). For every planned MRP order that enters the pool, the Operation Lengths (OPLs, see Figure 3) of all order operations are calculated. An OPL is the sum of the run and set-up times of the operation. Each order that enters the pool contributes to the Work Centre Pool 
Lengths (WCPLs), which are the sum of all OPLs for their respective work centres. The WCPLs are updated every period that the pool is loaded by planned MRP orders or releases orders to the cell. The Max (WCPLj), where $\mathrm{j}$ is a work centre of the order's routing, is defined as the Pool Delay Allowance for that order (Figure 3). The Throughput Time of an order equals to the sum of the total run and set-up times for all operations (Job Cycle Time) plus a Queue Allowance Factor. The queue allowance factor equals to the product of the average queue length (in hours) times the number of operations of the order. The average queue length is set to eight simulated hours and represents the operation lead- time for every work centre.

The goal is to keep the average lead times (total manufacturing lead time and throughput time) under control through the predetermined norms concerning the Pool Delay Allowance and the Queue Allowance Factor. An order with five operations, for example, will have an estimated throughput time equal to 40 hours plus the job cycle time. Thus the calculated total manufacturing lead time of an order is based on the time that the order spends in the pool waiting for its release plus the time that the order spends into the manufacturing cell being processed and waiting in work centre queues.

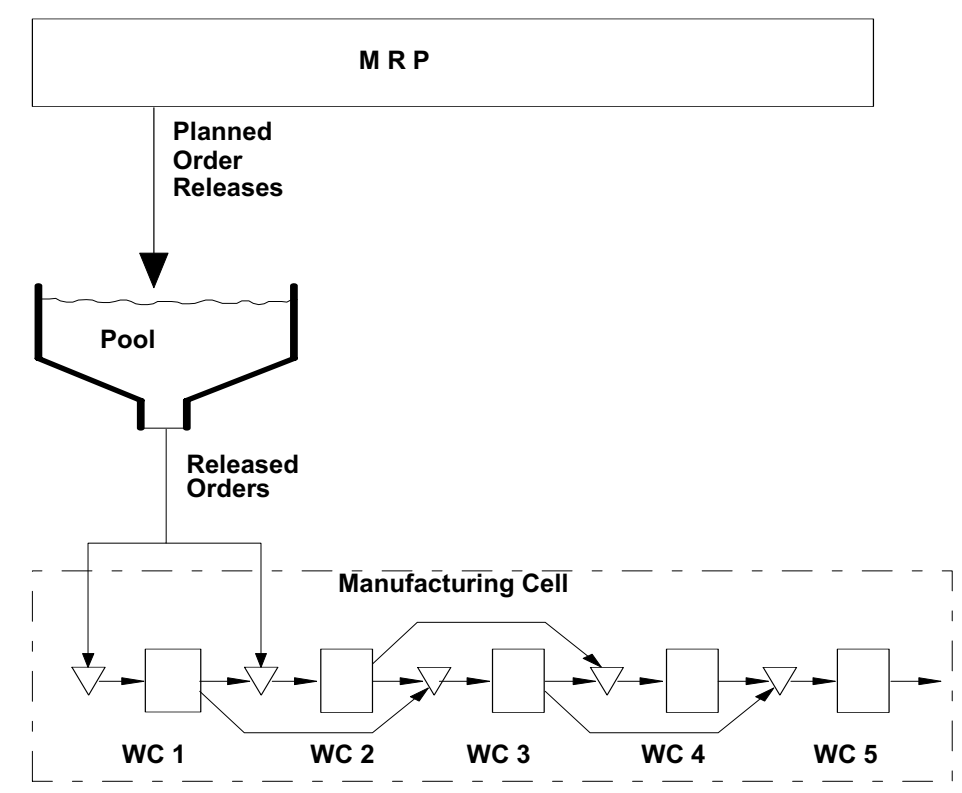

Fig. 2. Layout status of the manufacturing cell

\section{Input Control Mechanism}

The input control mechanism is also constructed according to the aggregate workload principle. It is based on the released backlog lengths for every work centre. For an order to be released into the cell, all the work centre released backlog lengths must be within minimum and maximum predetermined norm. The goal is to keep the average backlog lengths, which are the average operation lead times, balanced. 
The pool is responsible to control work centre backlogs by releasing orders in the cell or delaying them in the pool according to the norms of released backlog lengths.

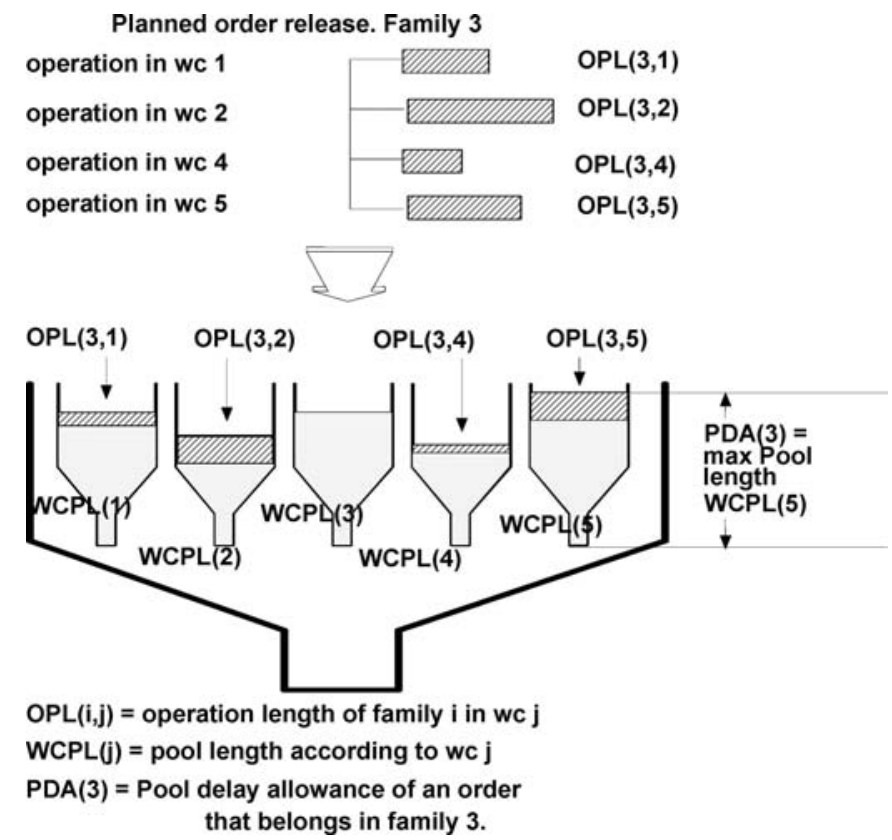

Fig. 3. Pool delay allowance of a shop order

\section{Dispatching rules}

In this study two dispatching rules used within the manufacturing cell are examined. The FIFO (First-In-First-Out) rule that supports the natural flow of the orders through the system, and the EDD (Earliest Due Date) rule that places the orders in the queues according to the earliest due date that has been calculated by the input control mechanism. There is also a dispatching principle that schedules the MRP planned orders to join the pool. This dispatching principle organises the position of the orders according to the minimum number of operations in each order.

\section{Types of models examined.}

There are three different types of models that are examined in this study. The manufacturing cell environment is the same for all model types. Model type I include an MRP system and an input control mechanism. Model type II includes only an input control mechanism, and model type III includes only an MRP system that releases orders to the cell without an input control mechanism. We can say that model types I and III represent a make-to-stock production environment (MTS) and model type II a make-to-order production environment (MTO).

We name the five different product mixes used in this study from A1 to A5 (Table 1). A classification system is used that helps recognition of the different types of models examined. Thus the code I/EDD/A1 represents models type I, who uses 
the EDD dispatching rule and the A1 products mix probability distribution. This codification of $3 * 2 * 5$ parameters leads to 30 different types of simulation experiments.

\subsection{Simulation experiments and results}

In order to test the models under the above mentioned conditions, pilot runs were executed to determine the appropriate values for the truncation point, the number of the samples (executions) in the same experiment and the total simulation run time. The determination of the truncation point was based on the Welch approach [17]. The truncation point was estimated to 1100 hours. The number of samples (replications), was estimated to 17 using the batch means approach, and the total simulation run time for each replication was estimated to 15000 hours.

The performance measures used to test the different models were: the average total manufacturing order lead time, average lateness, average tardiness and the percentage of tardy orders.

The simulation results are summarized in Table 2 and Figures 4 to 9 . They are based on comparisons between the models using the Student paired t-test. Conclusions that are drawn from the results are that by decreasing the number of families produced by the cell, the average manufacturing lead-time does not decrease respectively, no matter the dispatching rule used. The average lateness and tardiness are not influenced in a great degree by the change in the product mix, no matter the dispatching rule used and the way orders enter the cell, i.e. the type of model used. On the other hand, the percentage of tardy orders is explicitly influenced by changes in the product's mix structure.

Using the EDD dispatching rule, the percentage of tardy orders is significantly decreased independently of the product mix and the type of model used. The average manufacturing lead time is greatly reduced using the EDD dispatching rule instead of FIFO rule, which stands the same for a model that has an MRP system but does not use an input control mechanism. Generally with the use of EDD dispatching rule the average tardiness of the orders is reduced independently from the model type examined. In the case of model types I and II the values of average lateness are not influenced by the dispatching rule used and are approximately the same for both rules. This is not the case for model type III, where FIFO rule gives better results.

The way that orders enter the cell (model type used) influences the average manufacturing lead-time. When the pool is periodically loaded by a bulk of planned orders released from the MRP system, the result is the increase of manufacturing lead times and tardy orders. Using the pool the average tardiness is dramatically reduced independently of the model type.

In the case of MTS production environment, the use of the pool gives better results concerning the average lateness. In an MTS production system we have the accumulation of end product inventories, so that the input control mechanism is the preferred system according to the determination of order due date and due date dependability. There is not a great difference between the model types III (MTS environments) concerning the average order tardiness and I. 


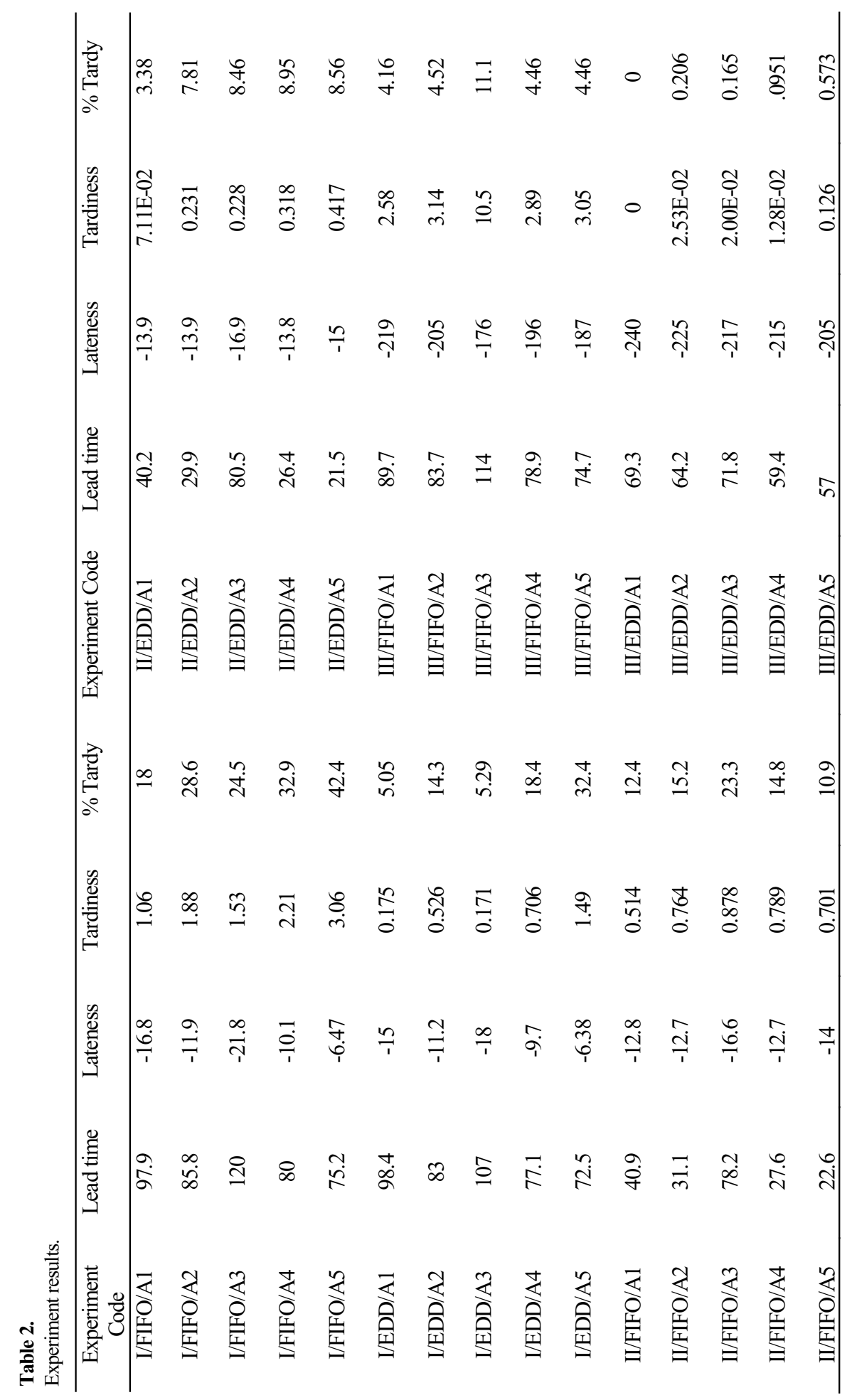


Using an input control mechanism it is not necessary to use different and complex dispatching rules in the waiting queues. It is more convenient to let the orders flow through the production system according with the way they are released from the pool. Some times a dispatching rule different from the FIFO rule, which supports the natural flow of orders through the system, may produce worse results.

Finally comparing the model types III, and I, that use the MPR planning system, we conclude that the input control mechanism did not increase the performance of the system concerning the average lead-time. In the case of the FIFO rule this difference is not significant. Consecutively in the case of EDD rule the difference is very significant. We can find the same results in Baker (1984) and Melnyk and Ragatz (1989).

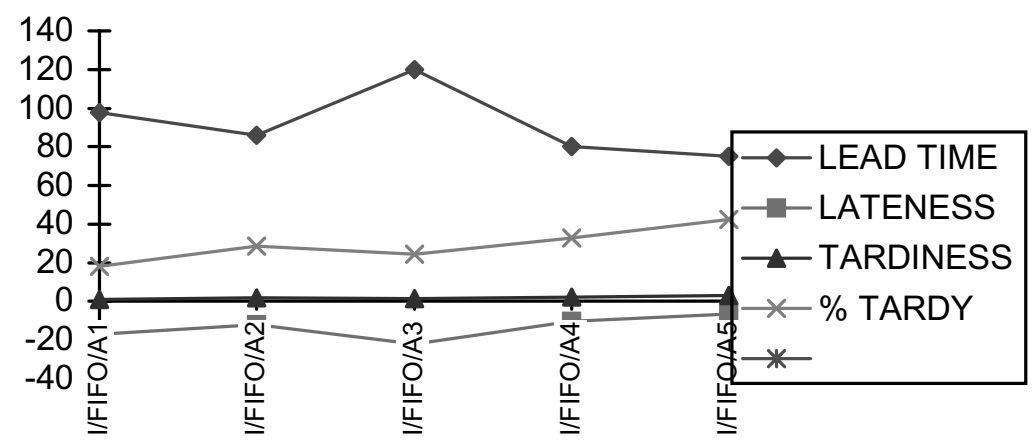

Fig. 4. Models type I, with FIFO for the five product mix distributions.

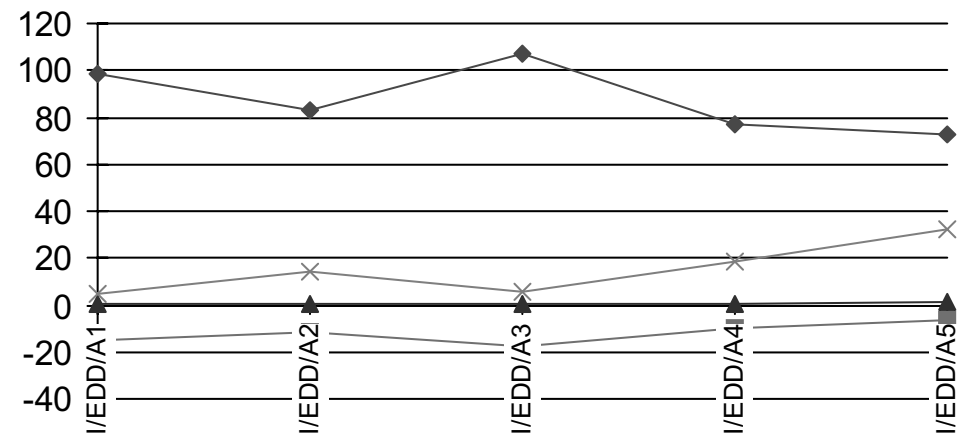

Fig. 5. Models type I with EDD for the product mix distributions. 


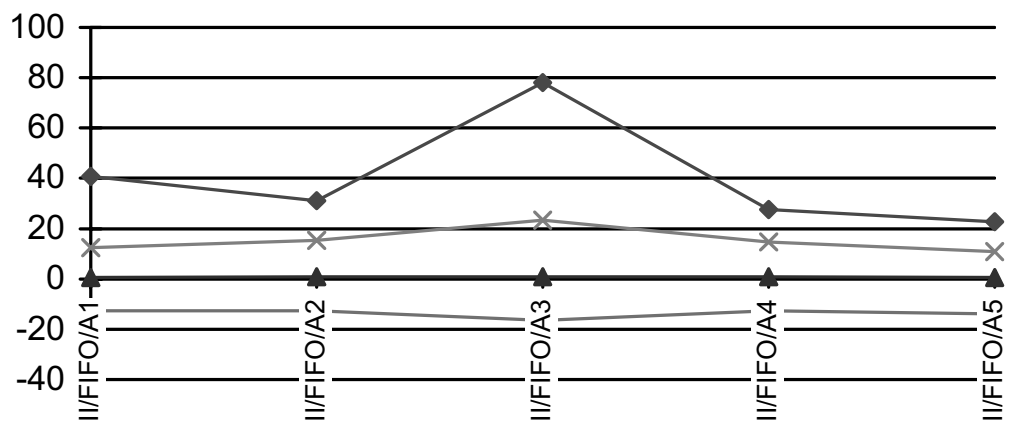

Fig. 6. Models type II with FIFO for the five product mix distributions.

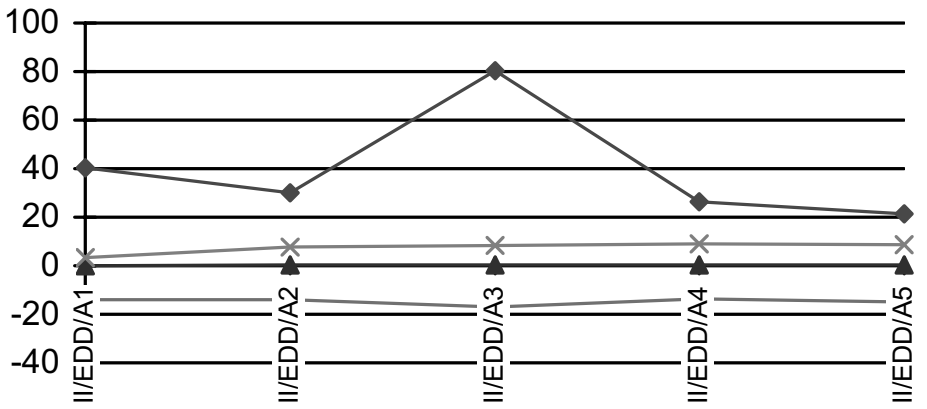

Fig. 7. Models type II with EDD for the five product mix distributions.

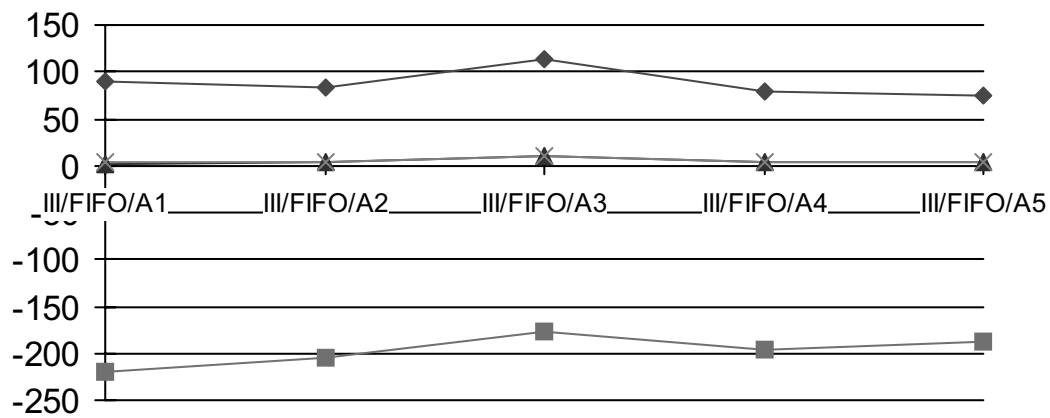

Fig. 8. Models type III with FIFO for the five product mix distributions. 


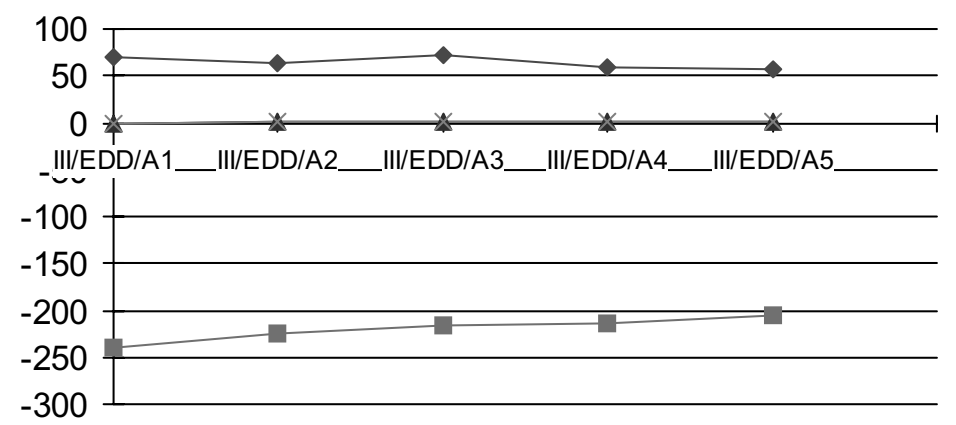

Fig. 9. Models type III with EDD for the five product mix distributions.

\section{Conclusions}

The main goal of this research was to extend the theory of orders release and workload control in general flow shops with disconnected line flow. The research started from the stance that although general flow shops that use standard MRP systems represent the majority of manufacturing systems, most of the input/output control and workload control theory concerns pure job shops. However, even in real life job shops there will be a more or less dominant flow direction. This dominant flow creates the need and the opportunity for a more thoroughly organized orders release system, which promotes the principle of balancing flow instead of capacity.

The tool to achieve balanced flow and controlled backlogs and lead times is the B-LOB technique and chart (Backlog Line of Balance). Our results are expected to be useful for those interested in including an orders release mechanism between the MRP system and the shop floor control system. Assumed is that the master plan (overall LOB-norm) is fixed by one central point in the manufacturing network, which the prime contractor who has direct contact to the customers. At the moment of an order release to the manufacturing network, there is a contribution to the aggregate released backlog of each partner/work centre, that the order will visit. After completion of the manufacturing step, the amount of work (set-up and process time) is deducted from the released backlog of the respective work centre. Every moment we know the released backlog of every partner/work centre, and by controlling the levels of the released backlogs in each partner/work centre, with the predetermined norms of the line-of-balance (B-LOB approach), we ensure that the backlog and the flow of work through the shop is smooth and controlled.

The status of this study is a simulated prototype written in the ARENA graphical simulation language. 


\section{References}

1. Baker, K.R., 1984, "The Effects of Input Control In a Simple Scheduling Model", Journal of Operations Management, Vol. 4, No. 2, pp. 99-112.

2. Bechte, W., 1988, "Theory and Practice of Load-oriented Manufacturing Control", International Journal of Production Research, Vol. 26, No. 3, pp. 375-395.

3. Bechte, W., 1994, "Load-oriented Manufacturing Control, Just-In-Time Production for Job Shops", Production Planning and Control, Vol.5, No.3, pp. 292307.

4. Bergamaschi et al., 1997, "Order Review and Release Strategies in a Job Shop Environment: A Review and Classification", Int. Journal of Production Research, Vol. 35, No.2, 339-420.

5. Bertrand, J.W.M. and J.C. Wortmann, 1981, "Production Control and Information Systems for Component Manufacturing Shops", Elsevier, Amsterdam.

6. Bertrand, J.W.M., Wortmann, J.C. and Wijngaard J., 1990, "Production Control. A Structural and Design Oriented Approach", Elsevier, Amsterdam.

7. Bertrand, J.W.M. and H.P.G. Van Ooijen, 1991, "Flow Rate Flexibility in Complex Production Departments", International Journal of Production Research, Vol. 29, No. 4, pp. 713-724.

8. Bertrand, J.W.M. and H.P.G. van Ooijen, 1996, "Integrating material coordination and capacity load smoothing in multi-product multi-phase production systems", Intern. J. of Prod. Econ. (46-47) 1-3, pp. 1-12.

9. Bestwick, P.F. and K. Lockyer, 1982, "Quantitative Production Management", Pitman Publishing, Mass.

10. Enns, S.T., 1995, “An integrated system for controlling shop loading and work flows", Int. Journal of Production Research, Vol.33, No. 0, pp. 2801-2820.

11. Glassey and Resende, 1998, "Closed-loop Job Release Control for VLSI Circuit Manufacturing”, IEEE Transactions on Semiconductor Manufacturing, 1, 1, 36-46.

12. Henry, L.C. and B.G. Kingsman, 1991, "Job Release: Part of a Hierarchical System to manage manufacturing lead times in make-to-order companies", J. Opl. Res. Soc., 42, pp. 871-883.

13. Hopp, W.J. and M.L. Spearman, 2000, "Factory Physics", McGraw Hill, Boston.

14. Irastorza, J.C. and R.H. Deane, 1974, "A Loading and Balancing Methodology for Job Shop Control", AIIE Transactions, Vol. 6, No. 4, pp. 302-307. 
15. Kingsman, B.G., Tatsiopoulos, I.P. and L.C. Hendry, 1989, "A Structural Methodology for Managing Manufacturing Lead Times In Make-to-Order Companies", European Journal of Operational Research, Vol. 40, pp. 196-209.

16. Kingsman, B., 2000, «Modelling Input-Output workload control for dynamic capacity planning in production planning systems», Int. J. of Production Economics, 68 (1), pp 73-93.

17. Land, M.J. and Gaalman G.J., 1996, "Workload Control Concepts in Job Shops: A Critical Assessment”, Int. Journal of Production Economics, Vol. 46-47, pp. 535548.

18. Melnyk, S.A. and G.L. Ragatz, 1989, "Order Review/Release: Research Issues and Perspectives", International Journal of Production Research, Vol. 27, No. 7, pp. 1081-1096.

19. Oosterman, B., Land, M., Gaalman, G., 2000, «The Influence of Shop Characteristics on Workload Control», Int. J. of Production Economics, 68 (1), pp. 107-119.

20. Plossl, G. and Wight, O., 1973, Capacity Planning and Control, Production and Inventory Management, $3^{\text {rd }}$ Qtr., pp. 31-67.

21. Ploss1, G.W. and W.E. Welch, 1979, "Decision Systems for Inventory Management and Production Planning", Reston Publ. Co.

22. Tatsiopoulos, I.P. and B.G. Kingsman, 1983, "Lead Time Management", European Journal of Operational Research, Vol. 14, pp. 351-358.

23. Tatsiopoulos, I.P, 1986, "Some Aspects of the Input/Output Methods for Managing Work-in-process Inventories", Engineering Costs and Production Economics, No. 15, pp. 235.

24. Tatsiopoulos. I.P., 1993, "Simplified production management software for the small manufacturing firm", Production Planning and Control, 15, 25-40.

25. Wein, 1988, Scheduling Semiconuctor in Wafer Fabrication, IEEE Transactions on Semiconductor Manufacturing, 1, 3, 115-130.

26. Welch, P.D., 1983, "The Statistical Analysis of Simulation Results", in the "Computer Performance Modelling Handbook", S.S. Lavenberg, ed., pp. 268-232, Academic Press, NY.

27. Wiendhal, H.P., 1995, "Load Oriented Manuacturing Control", Springer Verlag, Berlin.

28. Wight, O.W., 1970, "Input/Output Control: a Real Handle on Lead -Time", Production \& Inventory Management, Vol. 11, 3rd Quarter. 